\title{
Treatment during Primary HiV Infection Does Not Lower Viral Set Point But Improves CD4 Lymphocytes in aN Observational CoHort
}

\author{
C. Koegl ${ }^{1}$, E. Wolf 1 , N. Hanhoff 2 , H. Jessen ${ }^{3}$, K. Schewe ${ }^{4}$, M. Rausch ${ }^{5}$ J. Goelz ${ }^{2}$, A. Goetzenich ${ }^{2}$, \\ H. Knechten ${ }^{6}$, H. Jaeger ${ }^{7}$ and the Prime-DAG and Ac-DAG Study Groups* \\ ${ }^{1}$ MUC Research, Munich, Germany; ${ }^{2} \mathrm{DAGNAE}$ e.V., Berlin, Germany; ${ }^{3} \mathrm{HIV}$ outpatient practice, Berlin, Germany; \\ ${ }^{4}$ IPM/ICH-Studycenter, Hamburg; ${ }^{5}$ Private Practice, Berlin; Germany; ${ }^{6}$ PZB Aachen, Germany; ${ }^{7}$ MVZ Karlsplatz - HIV Research \\ and Clinical Care Centre Munich, Munich, Germany
}

\begin{abstract}
Objective: To investigate if early treatment of primary HIV-1 infection (PHI) reduces viral set point and/or increases CD4 lymphocytes.

Methods: Analysis of two prospective multi-centre PHI cohorts. HIV-1 RNA and CD4 lymphocytes in patients with transient treatment were compared to those in untreated patients. Time to CD4 lymphocyte decrease below $350 / \mu \mathrm{l}$ after treatment stop or seroconversion was calculated using Kaplan-Meier and Cox-PH-regression analyses.

Results: 156 cases of PHI were included, of which 100 had received transient HAART (median treatment time 9.5 months) and 56 remained untreated. Median viral load $(563000 \mathrm{cop} / \mathrm{ml}$ vs $240000 \mathrm{cop} / \mathrm{ml}$; $\mathrm{p}<0.001)$ and median CD4 lymphocyte $(449 / \mu \mathrm{l}$ vs. $613 / \mu \mathrm{l} ; \mathrm{p}<0.01)$ differed significantly between treated and untreated patients. Median viral load was 38056 copies $/ \mathrm{ml}$ in treated patients $(12$ months after treatment stop) and 52880 copies $/ \mathrm{ml}$ in untreated patients (12 months after seroconversion; ns). Median CD4 lymphocyte change was $+60 / \mu \mathrm{l}$ vs. $-86 / \mu \mathrm{l}(\mathrm{p}=0.01)$. Median time until CD4 lymphocytes decreased to $<350 / \mu$ l (including all patients with CD4 lymphocytes $<500 / \mu$ l during seroconversion) was 20.7 months in treated patients after treatment stop and 8.3 months in untreated patents after seroconversion $(p<0.01)$. Cox$\mathrm{PH}$ analyses adjusting for baseline VL, CD4 lymphocytes, stage of early infection and symptoms confirmed these differences.

Conclusions: Treatment during PHI did not lower viral set point. However, patients treated during seroconversion had an increase in CD4 lymphocytes, whereas untreated patients experienced a decrease in CD4 lymphocytes. Time until reaching CD4 lymphocytes $<350 / \mu$ l was significantly shorter in untreated than in treated patients including patients with CD4 lymphocytes $<500 / \mu$ l during seroconversion.
\end{abstract}

Key words: Primary HIV Infection, CD4 lymphocytes, antiretroviral therapy, HIV, viral set point

*See Appendix for study members.

\section{INTRODUCTION}

In chronically infected patients, use of highly active antiretroviral therapy (HAART) has been shown to be effective in suppressing viral replication and preventing immunological decline [1]. The viral set point is usually reached within six to twelve months after infection with the human immunodeficiency virus (HIV). The initial viral load during primary HIV infection (PHI) and the viral set point level are predictors of progression to clinical disease [2-4]. Early treatment of acute HIV-infection with highly active antiretroviral therapy may lead to a broader HIV-specific immune response and spontaneous control of viral replication [5-7]. An example of ideal viral control is observed in the "Berlin patient" [8]. Antiretroviral therapy was started in the acute phase of an HIV-infection with two treatment interruptions. Stopping HAART after approximately six months did not lead to an increase in viral load or to negative immunological effects during a follow-up of several years. The ability of early treatment to lower the viral set point was questioned by some studies. Yet only two studies were randomized controlled trials (both with an antiretroviral monotherapy), [9-10], and the patient numbers were small. It was concluded that early treatment, though it seems to control viral replication in a few patients, does not significantly influence the viral set point. CD4 lymphocytes were often not stated. It is unclear, whether or not initiation of HAART during PHI can change the long term progression to the acquired immunodeficiency syndrome (AIDS) [11-14].

With the current body of evidence, it is impossible to give a definite recommendation for commencing treatment in primary HIV- infection. The objectives of this study were to investigate, if early treatment of primary HIV-1 infection has an effect on the viral load set point and/or the cellular immune system defined as a delay in the time of antiretroviral treatment indication.

\section{Methods}

\section{Cohorts: Prime-DAG AND AC-DAG}

We conducted a pooled analysis of the two multi-centric, German cohorts of HIV seroconverters, PrimeDAG (Primary HIV-infection cohort of the DAGNAE) and Ac-DAG (Acute HIV-infection cohort of 
the DAGNAE), which were initiated by the DAGNAE (German Association of Physicians in Private Practice caring for HIV-infected individuals) in order to investigate treatment strategies and outcomes in acute HIVinfection. Patients aged 18 years or older were recruited from 42 health care centres in Germany. All patients with a documented acute HIV-infection after July 2001 could be included in the Prime-DAG cohort; patients with a documented acute HIV-infection after January 2003 could be included in the succeeding Ac-DAG cohort. There were no differences concerning inclusion criteria and management of acute HIV-infection between the two cohorts except of the recruitment time, so we performed a pooled analysis to increase the sample size. There were no antiretroviral treatment recommendations; every form of treatment including nontreatment was documented. Criteria for primary HIVinfection were a detectable viral load coupled with a negative ELISA or a positive ELISA with a documented Westernblot with less than 3 bands or a positive ELISA and a positive Westernblot with more than 3 bands with a negative HIV-test within the preceding six months. If the physician and patient opted for an early treatment, the therapy start was prior to or during seroconversion and, if possible, no more than 12 weeks thereafter. Changes in HIV-1 viral load and CD4 lymphocyte were assessed in treated patients and in untreated patients after seroconversion. Furthermore, the time to CD4 lymphocyte decrease below 350 cells $/ \mu 1$ (defining the point in time for treatment indication) was observed.

\section{LABOratory MEASUREMENTS AND Evaluations}

At enrolment, physicians reported the patients' mode of infection, their symptoms during PHI and performed a clinical examination. Primary HIV status was documented through ELISA and Westernblot. After enrolment, CD4 lymphocytes, HIV-1 RNA plasma levels (viral loads), start and stop times of antiretroviral treatment and occurrence of AIDS-defining events were monitored during seroconversion and at 3-months intervals thereafter. The observation time was 24 months. CD4 lymphocytes (flow cytometry) and viral loads (Roche Amplicor Ultra Sensitive 1.5) were measured locally by participating centres. The limit of detection of viral load was either 50 copies $/ \mathrm{ml}$ or 40 copies $/ \mathrm{ml}$.

\section{Statistical Analyses}

Virological and immunological parameters and their changes from baseline were summarized by median and interquartile range (IQR). Continuous variables were compared between subgroups using the MannWhitney U test including the $95 \%$ confidence interval (95\% CI). Kaplan-Meier analysis was used to assess the time to CD4 lymphocyte decrease below 350 cells $/ \mu$ l. Therefore, patients with (re) initiation of treatment were censored. Statistical significance was calculated by logrank testing and/or Breslow-GehanWilcoxon. Cox proportional hazards (Cox-PH) regression was used to investigate potential risk factors associated with the endpoint (CD4 lymphocytes $<350 / \mu \mathrm{l}$ ). Covariables were a) baseline viral load, b) baseline CD4 lymphocytes, c) the exactly time point of treatment start (before, during or after seroconversion) and d) the presence of symptoms like fever, lymphadenopathy, exanthema, pharyngitis, stomatitis or tonsillitis durind seroconversion. Results were presented as hazard ratios (HR) with 95\% CIs and p-values. Level of significance was defined as a p-value $\leq 0.05$. All analyses were performed with the statistical program StatView (Version 5.01, SAS Institute Inc., Cary, North Carolina, USA 1998).

\section{RESULTS}

From July 2001 until July 2004, 200 patients (191 men and 9 women) from 42 centres were enrolled into the PHI cohorts Prime-DAG und Ac-DAG. The median observation time was 27.0 months. The median age at time of HIV-infection was 35 years (range: 18 - 62 years). One-hundred-sixty-seven patients (83\%) stated homosexual contacts as their transmission risk, $16 \mathrm{pa-}$ tients $(8 \%)$ heterosexual contacts, 3 patients $(2 \%)$ injection drug use and 1 patient $(1 \%)$ needle stick injury. The risk was unknown for 13 patients $(6 \%)$. In 174 patients $(87 \%)$, clinical symptoms with or without known risk of transmission were the primary reason for HIV-testing. The main symptom (reported by the physician patient contact) was fever $(75 \%)$, followed by lymphadenopathy (49\%), exanthema (39\%) and pharyngitis, stomatitis or tonsillitis $(26 \%)$. In our cohort, 144 patients started with an antiretroviral treatment within 12 weeks of seroconversion and $56 \mathrm{pa}-$ tients remained untreated.

Of these 200 patients, 100 had received and stopped antiretroviral treatment during PHI and 56 had received no treatment. These 156 patients were included in our analysis. (The remaining 44 patients had continued ART and could not be included.) The initial recorded viral loads and CD4 lymphocytes for untreated and treated patients are shown in Table 1.

Table 1. Median viral load and median CD4 lymphocyte during seroconversion.

\begin{tabular}{|c|c|c|c|}
\hline Variable & $\begin{array}{l}\text { Treated Patients } \\
{[\mathrm{N}=100]}\end{array}$ & $\begin{array}{l}\text { Untreated Patients } \\
{[\mathrm{N}=56]}\end{array}$ & p-value \\
\hline $\begin{array}{r}\text { Viral load [copies/ml], Median } \\
\text { (IQR) }\end{array}$ & $\begin{array}{l}563,000 \\
(100-327 \text { million })\end{array}$ & $\begin{array}{l}240,000 \\
(463-6 \text { million })\end{array}$ & $<0.001$ \\
\hline CD4 lymphocyte $[1 / \mu \mathrm{l}]$ Median (IQR) & $449(120-1342)$ & $613(155-1543)$ & 0.003 \\
\hline CD4 percentage [\%], Median (IQR) & $29(8-50)$ & $26(8-44)$ & n.s. \\
\hline
\end{tabular}


Table 2. Viral load and absolute CD4 lymphocyte in treated patients at and after treatment stop.

\begin{tabular}{|c|c|c|c|c|}
\hline \multirow[b]{2}{*}{ time point } & \multicolumn{2}{|c|}{ Viral load } & \multicolumn{2}{|c|}{ CD4 lympocytes } \\
\hline & $\mathrm{N}=$ & Median (IQR) & $\mathrm{N}=$ & Median (IQR) \\
\hline at treatment stop & 100 & $\begin{aligned} &<50 \mathrm{cop} / \mathrm{ml}(<50-7,220) \\
& 1.69 \log (1.69-3.86)\end{aligned}$ & 100 & $799(392-1499)$ \\
\hline 3 months after stop & 82 & $\begin{array}{r}18,450 \mathrm{cop} / \mathrm{ml}(<50-2,160,000) \\
4.27 \log (1.69-6.33)\end{array}$ & 78 & $681(299-1304)$ \\
\hline 6 months after stop & 59 & $\begin{array}{r}25,300 \mathrm{cop} / \mathrm{ml}(<50-448,000) \\
4.40 \log (1.69-5.65)\end{array}$ & 58 & $627(250-1268)$ \\
\hline 12 months after stop & 44 & $\begin{array}{r}38,056 \mathrm{cop} / \mathrm{ml}(<50-492,000) \\
4.58 \log (1.69-5.69)\end{array}$ & 43 & $538(182-1130)$ \\
\hline
\end{tabular}

\section{Treated Patients}

Ninety-two $(92 \%)$ of the 100 treated patients received a triple combination and 8 patients $(8 \%)$ received a combination of four antiretroviral drugs. Eighty-three patients $(83 \%)$ were treated with a combination of NRTI and PI, another 12 patients $(12 \%)$ with a combination of NRTI and NNRTI and 5 patients (5\%) received NRTIs exclusively. Twenty-two patients $(22 \%)$ started treatment before seroconversion (6 patients presented with a detectable viral load coupled with a negative ELISA; 16 patients with a positive ELISA and a negative Westernblot), 78 patients $(78 \%)$ started during seroconversion (27 patients with a Westernblot equal or less than 3 bands and 51 patients with a Westernblot more than 3 bands; 45 of the these patients had a documented negative HIV test in the preceding 6 months and 6 patients had a second Westernblot within one month, showing the development of further bands). Viral load was below limit of detection in $65 \%$ of the patients after 3 months of treatment and in $72 \%$ after 6 months, respectively. After a median treatment time of 9.5 months (range: $2.1-28.7$ months, 9 patients with a treatment time $<5$ months) antiretroviral treatment was discontinued. Discontinuation was defined as a treatment stop of longer than 3 months. At discontinuation, 97 patients $(97 \%)$ had a viral load below 1000 copies $/ \mathrm{ml}$ and 82 patients (82\%) had an undetectable viral load. The median absolute CD4 lymphocyte was 799 cells/ $\mu$ l and the median CD4 percentage was $37 \%$. The progression of viral loads and CD4 lymphocytes in treated patients after preliminary treatment stop are shown in Table 2.

The median observation time after planned treatment stop was 17.3 months (range: 1.0 - 40.4 months). At treatment stop, 6 and 12 months after treatment stop, viral load and CD4 lymphocyte did not differ significantly between patients starting early (negative Westernblot), during (Westernblot $\leq 3$ band) or after seroconversion (Westernblot $>3$ bands). One year after treatment stop, viral load in three patients still remained below limit of detection. These three patients had started antiretroviral treatment with a positive ELISA and a positive Westernblot more than 3 bands.

\section{Comparison of Viral LoAd in Treated Patients after Treatment Stop with Untreated Patients}

Six months after treatment stop and seroconversion respectively, median viral load was significant lower in treated patients after treatment stop $(\mathrm{N}=59)$ as in untreated patients after seroconversion $(\mathrm{N}=41)$. Median viral load was 25,300 copies $/ \mathrm{ml}$ in treated patients and 96,400 copies $/ \mathrm{ml}$ in untreated patients $(\mathrm{p}<0.01)$. However, six months later, 12 months after treatment stop in treated and after seroconversion in untreated patients, there was no longer a significant difference between the two groups. Median viral load was 38.056 copies $/ \mathrm{ml}$ in treated patients $(\mathrm{N}=44)$ and 52,880 copies $/ \mathrm{ml}$ in untreated patients $(\mathrm{N}=37)(\mathrm{p}=$ n.s., Fig. 1).

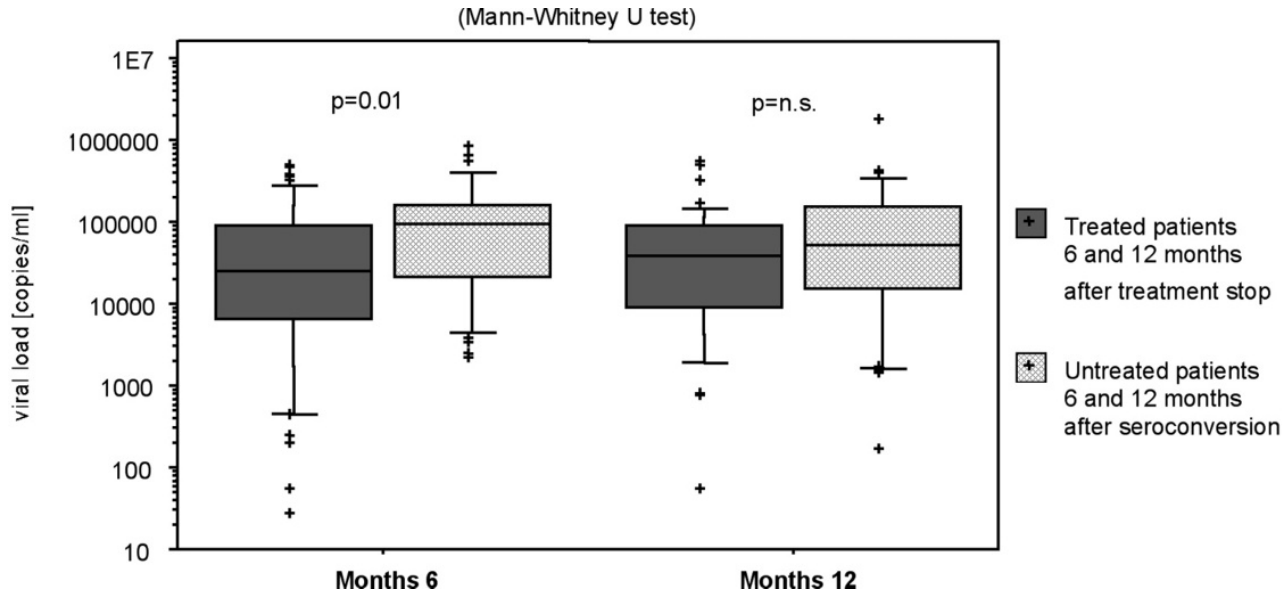

Fig. 1. Comparison of the progression of viral load in treated patients after treatment stop with untreated patients. Boxplot presentation including median values, 25th and 75 th percentiles. 
Comparison of CD4 Lymphocyte in Treated Patients after Treatment Stop With Untreated PATIENTS

Median absolute CD4 lymphocyte count was 627 cells $/ \mu \mathrm{l}$ in treated patients six months after treatment stop and 531 cells $/ \mu$ in untreated patients six months after seroconversion $(p=0.07)$. At month 12 , the median CD4 lymphocytes were similar in the two groups (538 cells $/ \mu \mathrm{l}$ in treated patients after treatment stop; 525 cells $/ \mu \mathrm{l}$ in untreated patients after seroconversion). Therefore, absolute CD4 lymphocytes did not differ significantly between treated or untreated patients. It is important to note, however, that there were significant differences in the CD4 lymphocytes at baseline (453 cells/ $\mu \mathrm{l}$ in treated patients and 629 cells $/ \mu 1$ in untreated patients during seroconversion). Figure 2 shows the changes in CD4 lymphocytes from seroconversion onwards of treated patients six and 12 months after treatment stop and of untreated patients six and 12 months after seroconversion. Six months after therapy stop, treated patients experienced an increase of 87 cells $/ \mu$ and untreated patients a decrease of 85 cells $/ \mu l$. Twelve months after treatment stop treated patients had an increase of 60 cells $/ \mu$ and untreated patients a decrease of 86 cells/ $\mu$ l. The differences between the two groups were significant at month $6(\mathrm{p}<0.001)$ and $12(\mathrm{p}=0.006)$.
Time to CD4 Lymphocyte Decrease BELOW $350 / \mu \mathrm{l}$

Overall, the time until CD4 lymphocytes decreased below $350 / \mu \mathrm{l}$ was not significantly different in treated patients and in untreated patients (data not shown). To exclude a bias caused by the significant difference in CD4 lymphocytes at the time of seroconversion, all patients with a CD4 lymphocyte below 500/ $\mu$ l during seroconversion were included in this part of the analysis. Thus, CD4 lymphocytes in treated patients ( $\mathrm{n}=$ $81 ; 344 / \mu \mathrm{l})$ and in untreated patients $(\mathrm{n}=18 ; 375 / \mu \mathrm{l})$ were comparable. Figure 3 shows the respective Kaplan-Meier curves. The median time until CD4 lymphocytes decreased below $350 / \mu$ l was 8.3 months in untreated and 20.7 months in treated patients stopping ART. This difference was highly significant $(\mathrm{p}<0.01$ (logrank; Mantel-Cox); p<0.001 (Breslow-GehanWilcoxon)). In a multivariable model of the Cox-PH analysis adjusting for treatment (HR: 0.50; 95\% CI: 0.25-0.98; $\mathrm{p}=0.04)$, baseline $\mathrm{VL}<50,000$ copies $/ \mathrm{ml}$ (HR: 0.74; 95\% CI: 0.23-2.38; $\mathrm{p}=\mathrm{ns}$ ), baseline CD4 lymphocytes < 500/ $\mu$ l (HR: 5.09; 95\% CI: 2.28-11.38; $\mathrm{p}<0.001)$, treatment start with a neg. WB (HR: 0.98; 95\% CI: 0.36-2.67; $\mathrm{p}=$ n.s.), and simultaneous appearance of symptoms like fever, lymphadenopathy, exanthema, pharyngitis, stomatitis or tonsillitis (HR: 1.25; 95\% CI: 0.31-4.98; $\mathrm{p}=$ n.s.), only treatment during se-
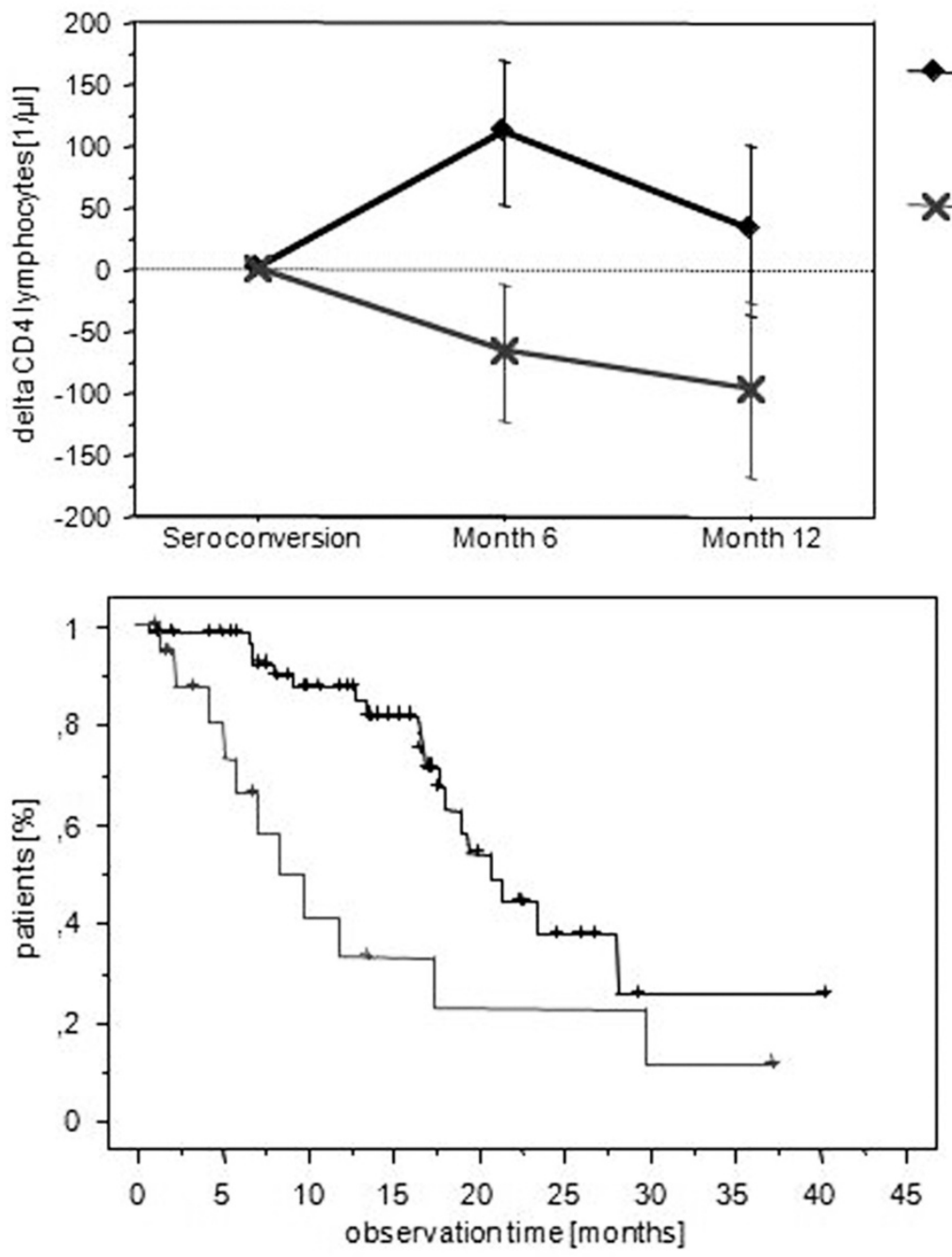

Treated patients 6 and 12 months after treatment stop

X Untreated patients 6 and 12 months after seroconversion

Fig. 2. Changes in absolute CD4 lymphocytes in treated patients after treatment stop and untreated patients.

\section{treated patients after treatment stop untreated patients after seroconversion $+\quad$ Censor times intreated patients \\ $+\quad$ Censor times in untreated patients}

Fig. 3. Kaplan-Meier analysis: Time to CD4 lymphocyte decrease below $350 / \mu \mathrm{l}$ in treated patients after treatment stop and untreated patients after seroconversion; including all patients with a CD4 lymphocyte $<500 / \mu l$ during seroconversion. 
roconversion and baseline CD4 lymphocytes were independent risk factors.

To account for treatment (re-)start prior to a CD4 decline to levels below $350 / \mu$, a sensitivity analysis was performed. Beside the CD4 endpoint, treatment restart in treated patients and any treatment initiation in untreated patients were considered as primary endpoints - irrespective of underlying reasons (which were not part of the case report form). In the subgroup of patients with less than $500 / \mu$ l CD4 lymphocytes at time of seroconversion, the median time to a CD4 lymphocyte decrease below $350 / \mu$ l was 8.3 months in untreated patients and 18.1 months in treated patients. Again, this difference was significant ( $\mathrm{p}=$ 0.03 (logrank; Mantel-Cox); p $<0.01$ (Breslow-GehanWilcoxon)).

\section{Discussion}

Herein, we report on one of the largest studies of primary HIV-infection. The majority of the patients were Caucasian men who have sex with men und who were symptomatic during seroconversion.

\section{EARLy TREATMENT AND Viral LOAD}

In our PHI cohort, early treatment did not change the viral load set point over an extended period. Six months after antiretroviral therapy stop, the viral load was significantly lower in initially treated patients than in untreated patients six months after seroconversion. However, after 12 months the viral load did no longer significantly differ. There were no differences between treated patients treated very early $(\mathrm{WB} \leq 3)$ or treated late (WB $>3$ bands) in a multivariable model of the Cox-PH analysis adjusting for treatment, but we cannot exclude that the sample size was too small to see a difference. Previous studies had shown a viral load reduction after stopping early treatment over a short observation time. Among these are the two randomized monotherapy studies of short courses of zidouvudine $[10,15]$. A small French cohort study - nine subjects were treated for 1 year - reported that viral load remained low even after 18 months off therapy [16]. However, other open-label studies stated that treatment during PHI does not influence the viral set point [17-19]. Markowitz and colleagues [18] treated $16 \mathrm{pa}-$ tients over a longer period (931-1822 days); 11 of these patients also received therapeutic vaccinations before discontinuing therapy. They reported that viral loads stabilized in only four subjects and that the viral load distribution of their patients was identical with the MACS natural history cohort [20]. Similar results were reported from a UK group, where 37 patients received a short course of therapy ( 3 months or until a viral load $<50$ copies $/ \mathrm{ml}$ was reached) [19]. After 48 weeks off therapy, the mean viral load level was 4.25 $\log 10$ copies/ml, which was comparable to a mean viral load of $4.3 \log 10$ copies/ $\mathrm{ml}$ in untreated seroconverters from the CASCADE cohort [21]. Desquilbet and his colleagues conclude that viral load 12 months after withdrawal of transient effective HAART started during primary infection is similar to viral load at the same time after infection in never-treated patients, suggesting that early HAART initiation does not lower the virological set-point [22]. They also did not find a correlation between the start of HAART (very early HAART during acute seroconversion and early HAART with two or more Western blot bands) and a lower viral load after HAART interruption. In contrast, Hecht et al. [23] concluded that initiation of HAART within two weeks of antibody seroconversion was associated with a viral load benefit for 24 weeks after the discontinuation of HAART, with a trend towards a long-term benefit. Later initiation of HAART was associated with a persistent but decreasing CD4 lymphocyte benefit and a loss of the viral load benefit by week 72 after discontinuation of treatment. In our cohort three patients were also able to control their viral replication. They started treatment with more than 3 bands in the Westernblot and had an undetectable viral load for 12,18 or 24 months after discontinuation of treatment.

\section{EARLY TREATMENT AND CD4 LYMPHOCYTES}

In our cohort, absolute CD4 lymphocytes did not differ significantly between treated patients 12 months after treatment stop and untreated patients 12 months after seroconversion. However, taking into account the significantly different baseline CD4 lymphocytes (at seroconversion), treated patients had an increase and untreated patients a decrease in CD4 lymphocytes. Therefore, considering the initial CD4 lymphocytes, treatment offers a CD4 lymphocyte advantage in treated patients. The most recent evaluation of early treatment during PHI did not consider CD4 lymphocytes [11]. Hecht et al. [23] found beneficial effects on CD4 lymphocytes for up to 72 weeks after termination of therapy. The differences between the treated group and the untreated group were statistically significant in a for CD4 lymphocyte and viral load adjusted analysis. Recently, Fidler et al. [24-26] compared seroconverters from a short course therapy cohort with untreated patients from the CASCADE cohort and concluded that a short course of HAART may delay CD4 lymphocyte decline. Later data from the CASCADE cohort described that patients treated for 12 months maintain higher CD4 lymphocytes [27]. On the other hand data from the ANRS Primo/Seroco groups presented by Seng et al. [28] showed that the benefit of transient HAART initiated during PHI on CD4 lymphocytes was rapidly lost when therapy was stopped again and CD4 lymphocyte loss after therapy stop was higher than the spontaneous loss after primary infection in natural history. The time to reach CD4 lymphocytes below 350/_l was not delayed in treated patients compared to patients without treatment. In our cohort the time until CD4 lymphocytes decreased below 350/ $\mu \mathrm{l}$ was also not significantly different in treated and untreated patients. Like in the ANRS Primo/Seroco groups, the CD4 lymphocytes during seroconversion were significantly different between treated and untreated patients $(442$ cells $/ \mu \mathrm{l}$ and 613 cells $/ \mu \mathrm{l})$. To exclude this possible bias, we performed a subanalysis including all patients with CD4 lymphocytes below $500 / \mu l$ during seroconversion. Now the time until

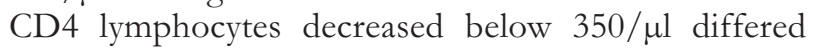


significantly in treated and untreated patients (20.7 and 8.3 months). Cox-PH analyses adjusting for baseline VL, CD4 lymphocytes, stage of early infection and simultaneous symptoms confirmed these differences. These results agree with the guidelines of the management und treatment of primary HIV-infection from the EACS [29] and data from recent cohorts and studies [30].

\section{LIMITATIONS}

One limitation of our cohort was the observational design of our study. There was no randomization of treatment. The decision to treat was associated with the viral load level and the CD4 lymphocyte during seroconversion. Baseline viral loads differed significantly between treated and untreated patients and only in $20 \%$ of the cases baseline viral load was quantified if it was higher than $>500,000$ copies $/ \mathrm{ml}$. There might be some bias due to the exclusion of 44 patients not stopping HAART during the observation period. This subgroup of treated patients did not differ in baseline characteristics like CD4 lymphocytes, viral load and symptoms from the other treated patients. It assumed that continuation of HAART in these patients was not due to an increased risk of disease progression, because it was a non-interventional cohort and stopping of HAART was only a recommendation and not a part of the study protocol. A second limitation was that the viral load in untreated patients six and 12 months after seroconversion was compared to the viral load in treated patients six and 12 months after treatment stop and thus later on in the course of HIVinfection (median 9 months).

\section{CONCLUSION}

The viral load did not differ significantly between treated patients 12 months after therapy stop and untreated patients 12 months after seroconversion. We therefore conclude that antiretroviral treatment during PHI does not lower the viral set point. Though CD4 lymphocyte counts did not differ significantly between treated patients 12 months after treatment stop and untreated patients 12 months after seroconversion, change in CD4 lymphocytes from baseline did. Patients with transient treatment had an increase in CD4 lymphocytes, whereas untreated patients experienced a decrease in CD4 lymphocytes. Time until reaching CD4 lymphocytes $<350 / \mu$ l was significantly shorter in untreated than in treated patients for patients with CD4 lymphocytes $<500 / \mu$ l during seroconversion.

\section{APPENDIX}

\section{Participating German Centers and Contributing Physicians}

Dr. W. Becker, Munich; Dr. I. Becker-Boost, Duisburg; Dr. D. Berzow, Hamburg; Dr. B. Bieniek, Berlin; Drs. J. Brust, D. Schuster, Mannheim; Dr. S. Dupke, Berlin; Dr. S. Fenske, Hamburg; Dr. H. J. Gellermann, Hamburg; Drs. R. Gippert, P. Hartmann, Muenster; Dr. B. Hintsche, Berlin; Drs. H. Jaeger, E. Jaegel-Guedes, Munich; Dr. H. Jessen, Berlin; Dr. J. Gölz, Berlin; Dr. J. Koelzsch, Berlin; IFI Institut; Prof. Dr. E. B. Helm, Dr. G. Knecht, Frankfurt; Dr. H. Knechten,
Aachen; Drs. L. Locher, P. Gute, Frankfurt; Dr. S. Mauruschat, Wuppertal; Dr. S. Mauss, Duesseldorf; Dr. V. Miasnikov, Duesseldorf; Dr. F. A. Mosthaf, Karlsruhe; Drs. M. Rausch, M. Freiwald, Berlin; Dr. B. Reuter, Berlin; Dr. H.-M. Schalk, Vienna; Dr. B. Schappert, Mainz; Dr. E. Schnaitmann, Stuttgart; Dr. L. Schneider, Fuerth; Dr. W. SchülerMaué, Berlin; Dr. C. Schuler, Berlin; Dr. T. Seidel, Jena; Dr. W. Starke, Wiesbaden; Drs. A. Ulmer, M. Müller, Stuttgart; Drs. L. Weitner, K. Schewe, Hamburg; Dr. C. Zamani, Hannover; Hospital Augsburg (III. Med. Klinik), Dr. A. Hammond, Augsburg; University Hospital Essen, Dr. K. Ross, Essen; Hospital Frankfurt (Infektiologicum Frankfurt City), Prof. Dr. A. Bottlaender, Frankfurt; University Hospital Kiel, Dr. C. Hoffmann, Kiel; Hospital Konstanz, Dr. A. Dix, Konstanz; Klinikum der Universität Muenchen, Innenstadt-Medizinische Poliklinik Munich, University Hospital Regensburg, Dr. A. Schneidewind, Regensburg; University Hospital Rostock, Dr. M. Lademann, Rostock.

Acknowledgments: We thank all the participating patients and physicians (see Appendix) of the Prime-DAG and AC-DAG cohorts. Prime-DAG was made possible through the unconditional financial supports from Abbott und GlaxoSmithKline. Ac-DAG was made possible through the unconditional financial supports from Abbott, Boehringer Ingelheim, Bristol-Myers Squibb, Gilead Sciences, GlaxoSmithKline, Hoffmann-La Roche and MSD Sharp \& Dohme.

\section{REFERENCES}

1. Gulick RM, Mellors JW, Havlir D, Eron JJ, Gonzalez C, McMahon D, et al. Treatment with indinavir, zidovudine, and lamivudine in adults with human immunodeficiency virus infection and prior antiretroviral therapy. $\mathrm{N}$ Engl J Med 1997, 337:734-739.

2. Musey L, Hughes J, Schacker T, Shea T, Corey L, McElrath MG. Cytotoxic-T-cell responses, viral load and disease progression in early human immunodeficiency virus type 1 infection. N Engl J Med 1997; 337:1267-74

3. Farzadegan H, Henrard DR, Kleeberger CA, Schrager L, Kirby AJ, Saah AJ, et al. Virologic and serologic markers of rapid progression to AIDS after HIV-1 seroconversion. J Acquir Immune Defic Syndr Hum Retrovirol 1996, 13:448-455

4. Blattner WA, Oursler KA, Cleghorn F, Charurat M, Sill A, Bartholomew C, et al. Rapid clearance of virus after acute HIV-1 infection: correlates of risk of AIDS. J Infect Dis 2004; 189:1793-1801.

5. Rosenberg ES, Altfeld M, Poon SH, Phillips MN, Wilkes BM, Eldridge RL, et al. Immune control of HIV-1 after early treatment of acute infection. Nature 2000 Sep 28; 407:523-6.

6. Oxenius A, Price DA, Easterbrook PJ et al. Early highly active antiretroviral therapy for acute HIV-1 infection preserves immune function of $\mathrm{CD} 8+$ and $\mathrm{CD} 4+\mathrm{T}$ lymphocytes. Proc Natl Acad Sci USA. 2000; 97:3382-3387

7. Jansen CA, De Cuyper IM, Steingrover R, Jurriaans S, Sankatsing SU, Prins JM, et al. Analysis of the effect of highly active antiretroviral therapy during acute HIV-1 infection on HIV-1 specific CD4 T-cell functions. AIDS 2005; 11:1145-1154.

8. Lisziewicz J, Rosenberg E, Lieberman J, Jessen H, Lopalco L, Silicano R, et al. Control of HIV despite the discontinuation of antiretroviral therapy. N Engl J Med 1999 May 27; 340(21):1683-4.

9. Kinloch-De Loes S, Hirschel BJ, Hoen B, Cooper DA, Tindall B, Carr A, et al. A controlled trial of zidovudine in primary human immunodeficiency virus infection. $\mathrm{N}$ Engl J Med 1995, 333: 408-413. 
10. Niu MT, Bethel J, Holodniy M, Standiford HC, Schnittman SM. Zidovudine treatment in patients with primary (acute) human immunodeficiency virus type 1 infection: a randomized, double-blind, placebo-controlled trial. DATRI 002 Study Group. Division of AIDS Treatment Research Initiative. J Infect Dis 1998, 14:397-403.

11. Smith DE, Walker BD, Cooper DA, Rosenberg ES, Kaldor JM. Is antiretroviral treatment of primary HIV infection clinically justified on the basis of current evidence? AIDS 2004, 18: 709-718.

12. Sterling TR, Chaisson RE, Keruly J, Moore RD. Improved outcomes with earlier initiation of highly active antiretroviral therapy among human immunodeficiency virus-infected patients who achieve durable virological suppression: longer follow-up of an observational cohort study. J Infect Dis 2003;188:1659-65.

13. Kinloch-de Loes S. Treatment of acute HIV-1 infection: is it coming of age? J Infect Dis 2006;194:721-4.

14. Berrey MM, Schaker T, Collier AC, et al. Treatment of primary human immunodeficiency virus type 1 infection with potent antiretroviral therapy reduces frequency of rapid progression to AIDS. J Infect Dis 2001;183:146675.

15. Lindback S, Vizzard J, Cooper DA, Gaines H. Long-term prognosis following zidovudine monotherapy in primary human immunodeficiency virus type 1 infection. J Infect Dis 1999, 179:1549-1552.

16. Girard PM, Schneider V, Dehee A, Mariot P, Jacomet C, Delphin N, et al. Treatment interruption after one year of triple nucleoside analogue therapy for primary HIV infection. AIDS 2001, 15:275-277.

17. Kaufmann DE, Lichterfeld M, Altfeld M, Addo MM, Johnston MN, Lee PK, et al. Limited durability of viral control following treated acute HIV infection. PloS Med 2004; 1: e36.

18. Markowitz M, Jin X, Hurley A, Simon V, Ramratnam B, Louie $\mathrm{M}$, et al. Discontinuation of antiretroviral therapy commenced early during the course of human immunodeficiency virus type 1 infection, with or without adjunctive vaccination. J Infect Dis 2002; 186:634-43.

19. Fidler S, Oxenius A, Brady M, Clarke J, Cropley I, Babiker A, et al. Virological and immunological effects of short-course antiretroviral therapy in primary HIV infection. AIDS 2002, 16:2049-2054.

20. Lyles RH, Munoz A, Yamashita TE, Bazmi H, Detels R, Rinaldo CR, et al. Natural history of human immunodeficiency virus type 1 viremia after seroconversion and proximal to AIDS in a large cohort of homosexual men. Multicenter AIDS Cohort Study. J Infect Dis 2000, 181:872880.

21. Cascade. Time from HIV-1 seroconversion to AIDS and death before widespread use of highly-active antiretroviral therapy: a collaborative re-analysis. Collaborative Group on AIDS Incubation and HIV Survival including the CASCADE EU Concerted Action. Concerted Action on SeroConversion to AIDS and Death in Europe. Lancet 2000, 355:1131-1137
22. Desquilbet L, Goujard C, Rouzioux C, Sinet M, Deveau C, Pellegrin I, for the PRIMO and SEROCO Study Groups. Does transient HAART during primary infection lower the virological set-point? AIDS 2004; 18:23612369.

23. Hecht FM, Wang L, Collier A, Little S, Markowitz M, Margolock J, et al. A multicenter observational study of the potential benefits of initiating combination antiretroviral therapy during acute HIV infection. J Infect Dis 2006;194:725-33).

24. Fidler S, Fox J, Touloumi G; Pantazis N; Porter K, Babiker A, et al.; the CASCADE Collaboration. Slower CD4 Cell Decline Following Cessation of a 3 Month Course of HAART in Primary HIV Infection: Findings From an Observational Cohort. AIDS. 2007; 21(10): 1283-1291.

25. Fidler S, Fraser C, Fox J, Tamm N, Griffin JT, Weber J. Comparative potency of three antiretroviral therapy regimes in primary HIV infection. AIDS 2006; 20:247252.

26. CASCADE Collaboration. Changes in the uptake of antiretroviral therapy and survival in persons with known duration of HIV infection in Europe. HIV Med 2000; 1: 224-231.

27. Pantazis N, Touloumi G, Vanhems P, Gill J, Bucher HC, Porter $\mathrm{K}$. The effect of antiretroviral treatment of different durations in primary HIV infection. AIDS 2008;22: 2441-50.

28. Seng R, Goujard C, Desquilbet L, Sinet M, Rouzioux C, Deveau C, et al. Rapid CD4+ cell decrease after transient cART initiated during primary HIV infection (ANRS PRIMO and SEROCO cohorts). J Acquir Immune Defic Syndr 2008; 49(3): 251-258.

29. Clumeck N, Pozniak A, Raffi F. European AIDS Clinical Society (EACS) guidelines for the clinical management and treatment ofHIV-infected adults. HIV Med 2008; 9:65-71.

30. Fidler S, Fox J, Porter K, Weber J. Primary HIV infection: to treat or not to treat? Curr Opin Infect Dis 2008; 21:4-10.

Received: December 17, 2008 / Accepted: June 2, 2009

Address for correspondence:

Ph.D. Christine Koegl

MUC Research

Karlsplatz 8

80335 Munich,

Germany

Tel.: $\quad+4989 / 5998933$

Fax: $\quad+4989 / 59989353$

E-mail: cko@mucresearch.de 